\title{
Non-Linear Optical Effects in Au Nanoparticle-Deposited ZnO Nanocrystalline Films
}

\author{
Katarzyna Ozga ${ }^{1, a}$, Toshiyuki Kawaharamura² ${ }^{2}$ Akrajas Ali Umar ${ }^{3}$, \\ Munetaka Oyama ${ }^{3}$, Andrzej Slezak ${ }^{1}$, Shizuo Fujita ${ }^{3}$,Ivan Kityk ${ }^{4, b}$ \\ ${ }^{1}$ Institute of Biology and Biophysics, Technical University of Czestochowa, Al. Armii Krajowej 36, \\ Czestochowa 42-200, Poland \\ ${ }^{2}$ Department of Electronic Engineering and Science, Kyoto University, Nishikyo-ku, Kyoto 615- \\ 8510, Japan \\ ${ }^{3}$ International Innovation Center, Kyoto University, Nishikyo-ku, Kyoto 615-8520, Japan \\ ${ }^{4}$ Silesian University of Technology, Faculty of Chemistry, Strzody 9, Gliwice 44-100, Poland \\ a cate.ozga@wp.pl (corresponding author), bi.kityk@ajd.czest.pl
}

received paper 28.10.2007, received revised paper, 22.12.2007 accepted date, 30.12.2007

Keywords: Nanocrystalline materials; Non-linear Optics.

\begin{abstract}
Applying a bicolor coherent treatment of a Nd-YAG laser with wavelength $1.32 \mu \mathrm{m}$ and its second harmonic generation, we have investigated photoinduced SHG in Au nanoparticledeposited $\mathrm{ZnO}$ nanocrystallinne (NC) films. We have established that coexistence of the such crystallites gives substantially better results compared to the pure $\mathrm{ZnO} \mathrm{NC}$ deposited onto the glass substrate. It was shown that the value of the second order susceptibility obtained for the large incident angles of the fundamental and writing beams is equal to about $23 \mathrm{pm} / \mathrm{V}$. The better results are obtained during the phototreatment at temperatures near the $60{ }^{\circ} \mathrm{C}$ for the Au doped samples and is almost non-sensitive to temperature for the pure samples. The further increase of the temperature leads to decay of the optical second harmonic generation
\end{abstract}

\section{Introduction}

Recently one can observe an enhanced interest to $\mathrm{ZnO}$ films and nanocrystallites during search and design of new materials for quantum electronics [1-4]. However in all the investigations the second order optical effects, particularly optical second harmonic generation were related with the degree of orientation of the $\mathrm{ZnO}$ films or versus the substrate.

Among the numerous nonlinear optical materials [5] ZnO seems to be more promising due to the excellent optical and photomechanical properties, possibility to deposit the layers on the different kinds of substrates [6]. Moreover, the measurements performed for the thin $\mathrm{ZnO}$ films of different crystallinity [7] have shown relevant second order susceptibility (up to $10 \mathrm{pm} / \mathrm{V}$ ) at wavelength $1060 \mathrm{~nm}$. It was shown that this parameter is crucially dependent on the degree of the film crystallinity and the grain boundaries and interfaces play in this case a principal role. It is interesting to note that the moderate SHG signals were obtained even for the films deposited by a simplified and chip spray technology [10]. It was typical that most of the first experiments were performed for the case when the wurtzite-like $c$-axis was oriented perpendicularly to the substrate plane [11-13]. There were different approaches directed on the enhancement of the second order susceptibilities. In particular, one of the approaches consisted in the deposition of the hexagonal films with $c$ axis orientation lying intra the substrate plane [14] that allowed enhancing the corresponding susceptibility up to $30 \mathrm{pm} / \mathrm{V}$. Another approach has applied critical resonance frequencies approaching the energy gap. The maximal value of the second order susceptibility was found to be equal about $83 \mathrm{pm} / \mathrm{V}$ that is 14 times larger than in the bulk materials and is the highest among the reported for today. One of the approach consisted in the doping of the $\mathrm{ZnO}$ film by the highly polarized $\mathrm{F}$ ions that allowed receiving the value of the linear electrooptic coefficient equal to about $17 \mathrm{pm} / \mathrm{V}$ in the blue spectral range. In the Ref. [15] it was established that decreasing of the 
film thickness is followed by the substantial enhancement of the SHG independently on the technology. However it contradicts to the data of other researches showing that using of the rfmagnetron sputtering or plasma-enhanced chemical vapor deposition may influence crucially the values of the SHG. Moreover, using the bicolor optical treatment [16] it was shown the substantial influence of the substrate on the induced optical susceptibilities. In the present work we apply our previous method of UV-induced SHG to explore SHG behavior [17]. In the present work we propose to enhance the susceptibilities by $>$ formation of the nanocomposites possessing coexistence of the $>$ semiconducting $\mathrm{ZnO}$ nanocrystlalties and metallic Au nanoparitlcesThe $\mathrm{ZnO}$ is necessary as an excellent nonliner optical materials whichis good fitted to surface plasmon resonances of the gold NP.

\section{Experimental}

Sample Preparation. $\mathrm{ZnO}$ thin films were prepared on glass supports (a piece of soda-glass, 15 $\mathrm{mm} \times 15 \mathrm{~mm}$ ) by a linear source ultrasonic spray chemical vapor deposition (LS-CVD) method [18, 19]. Briefly, an ethanol-water solution containing $0.05 \mathrm{M}$ zinc acetate, $\mathrm{Zn}\left(\mathrm{CH}_{3} \mathrm{COO}\right)_{2} \cdot 2 \mathrm{H}_{2} \mathrm{O}$, was sprayed as the mist that was composed of super-liquid-particles (ca. $1 \mu \mathrm{m}$ ) by an ultrasonic transducer. The mist was carried onto the surface of the substrate, and pyrolysis was performed to form the $\mathrm{ZnO}$ nanocrystallite films. To achieve a constant supply of source mists, dual $\mathrm{N}_{2}$ gas flow systems were used, i.e., one flow for the direct supply of source mists at $1.0 \mathrm{~L} / \mathrm{min}$, and the other flow as a carrier at $7.0 \mathrm{~L} / \mathrm{min}$. The temperature to grow $\mathrm{ZnO}$ films was $500{ }^{\circ} \mathrm{C}$, and the pyrolysis time was $10 \mathrm{~min}$.

For attaching Au nanoparticles on the surfaces of $\mathrm{ZnO}$, we used a seed-mediated growth method for the surface modifications [20]. This method was developed following the the seed-mediated growth method for preparing Au nanorods in aqueous solution by Murphy and coworkers [20, 21]. As the actual procedures, prior to the modification, a piece of $\mathrm{ZnO}$ coated glass, whose size was ca. $7 \mathrm{~mm} \times 7 \mathrm{~mm}$, was rinsed with water and dried with a stream of nitrogen. Then, the $\mathrm{ZnO}$ was immersed in the seed solution that contained gold nanoparticles of ca. $4 \mathrm{~nm}$, which was prepared by adding $0.5 \mathrm{~mL}$ of cooled aqueous solution of $0.1 \mathrm{M} \mathrm{NaBH}_{4}$ into $19.5 \mathrm{~mL}$ of aqueous solution containing $0.25 \mathrm{mM} \mathrm{HAuCl}_{4}$ and $0.25 \mathrm{mM}$ trisodium citrate [22]. After leaving $2 \mathrm{hrs}$., the $\mathrm{ZnO}$ substrate was then taken out and washed with flushing pure water. After drying the $\mathrm{ZnO}$ surface, it was immersed in the growth solution and left undisturbed for $1 \mathrm{hr}$. The growth solution was prepared by adding aqueous solutions of $2.5 \mathrm{~mL}$ of $0.01 \mathrm{M} \mathrm{HAuCl}_{4}, 0.5 \mathrm{~mL}$ of $0.1 \mathrm{M}$ ascorbic acid, and $0.5 \mathrm{~mL}$ of $0.1 \mathrm{M} \mathrm{NaOH}$, into $90 \mathrm{~mL}$ of aqueous solution of $0.1 \mathrm{M}$ cetyltrimethylammonium bromide (CTAB) [23]. Finally, the substrate was washed again with distilled water and then dried with nitrogen.

With these treatments, in particular, in the first immersion into the seed solution, $\mathrm{Au}$ and $\mathrm{Ag}$ nanoparticles were found to attach on the ITO surfaces [24]. It is considered that small nanoparticles tend to attach via physi-sorption on the surfaces judging from the experimental results. Such attachment of small nanoparticles is known as a precursor method in the field of catalysis [23, 24].

While we reported optical properties of metal nanoparticle-attached ITO prepared with this seedmediated growth method for surface modification [18], it was applied to the modification of $\mathrm{ZnO}$ in the present work. For modifying the ITO surfaces, we left the samples in the growth solution for 24 hrs. However, in the case of the present $\mathrm{ZnO}$, the immersion for $24 \mathrm{hrs}$ caused the removing of $\mathrm{ZnO}$ films. Thus, we adopted the growth time of $1 \mathrm{hr}$, though the grown size of Au nanoparticles were smaller than those prepared in the case of ITO [23]. The color of the ZnO substrate prepared in the seed-mediated growth procedure was red-purple as mentioned later, and the color was much thicker than that of $\mathrm{ZnO}$ prepared by immersing just in the seed solution. So, we used the $\mathrm{ZnO}$ samples prepared by treating in the seed solution first, and then in the growth solution for $1 \mathrm{hr}$., in this work.

The JEOL JSM-7400F field emission scanning electron microscopy (FE-SEM) was used to characterize the surface morphology of $\mathrm{ZnO}$ films. 


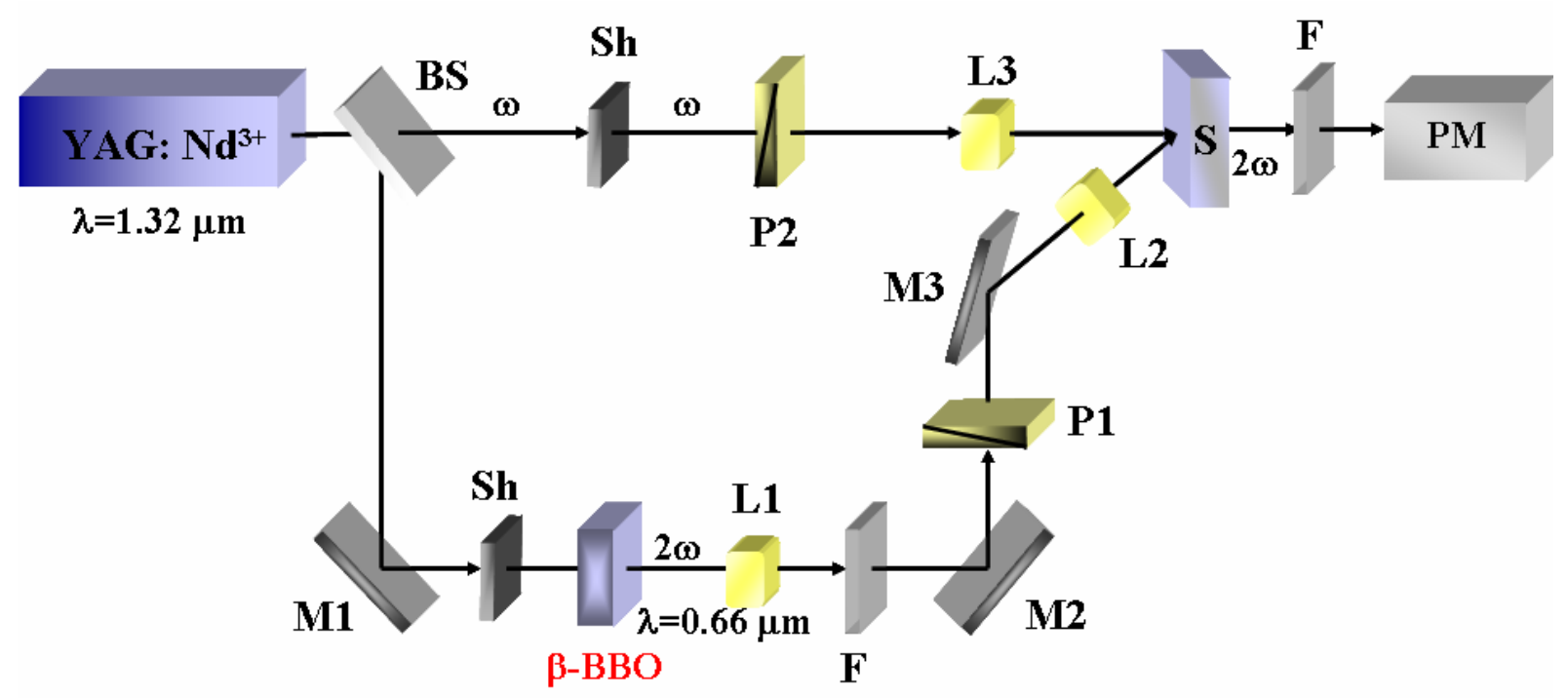

Fig. 1. Principal schema of measurement set-up.

Optical set-up. The photoinducing pulsed Nd:YAG laser providing the $1320 \mathrm{~nm}$ wavelength operates with a pulse duration of $40 \mathrm{ps}$ and a frequency of $100 \mathrm{~Hz}$ (see Fig. 1). The optical second harmonics are generated by a single phase-matched $\beta$-BBO crystal. The pumping beam consists of a combination of the fundamental and the doubled frequency wavelengths. The ratio $(r)$ of their intensities is changed from 6 to 90 by varying the KTP crystal angle from 5 to 28 degree with respect to the incident fundamental beam. A beam-splitter is used for the independent control of the incident light from the fundamental $\mathrm{Nd}$ :YAG laser. The polarisation of the incident bicolour coherent light on the sample is performed by Glahn polariser. A synchronisation of the chopper with the Nd-YAG laser is ensured for a simultaneous light interruption. At the same time, the light source supplies a probing non-monochromatic beam slavered to the chopper whose desired frequency can attain $100 \mathrm{kHz}$ The polarisation of the incident light is done with the polariser before irradiation of the sample. The monitoring of changes in the optical transmission spectrum is performed with the monochromator of about $2 \mathrm{~nm}$ spectral resolution directly connected with the CCD camera.

\section{Results and discussion}

FE-SEM observation of $\mathrm{ZnO}$ surfaces. Figure 2 shows the typical FE-SEM images of ZnO before and after the seed-mediated growth treatment. Compared with the surface image observed before treatment (Fig. 2a), small dots of ca. $20 \mathrm{~nm}$ were observed to attach at the vicinities of $\mathrm{ZnO}$ nanoclystallites after the seed mediated growth treatment. The dots were apparently brighter compared with the crystals of $\mathrm{ZnO}$ in the direct operations of FE-SEM. While the original $\mathrm{ZnO}$ sphere crystals near $50 \mathrm{~nm}$ were observed with bright contract in Fig. 2a, the brightness observed in the operations was different from those of the small dots in Fig. 2b. Thus, the small dots in Fig. 2b are considered to be attached and grown $\mathrm{Au}$ nanoparticles on the $\mathrm{ZnO}$ surface, which would be reasonably deduced from the results of the modification of ITO. Furthermore, the result of eye inspection also supported the attachment of $\mathrm{Au}$ nanoparticles because the pinkish color was observed after treating in the seed solution, and the color become denser after treating in the growth solution. Although the grown size of Au nanoparticles was limited to small (ca. $20 \mathrm{~nm}$ ) due to the 
reason mentioned in the experimental section, i.e. the removal of $\mathrm{ZnO}$ film, we used the $\mathrm{Au}$ nanoparticles attached $\mathrm{ZnO}$ samples as in Fig. $2 \mathrm{~b}$ for the optical measurements. The changes in the appearance of the $\mathrm{ZnO}$ nanocrystallite film are inferred to be caused by the dissolution in the growth solution.
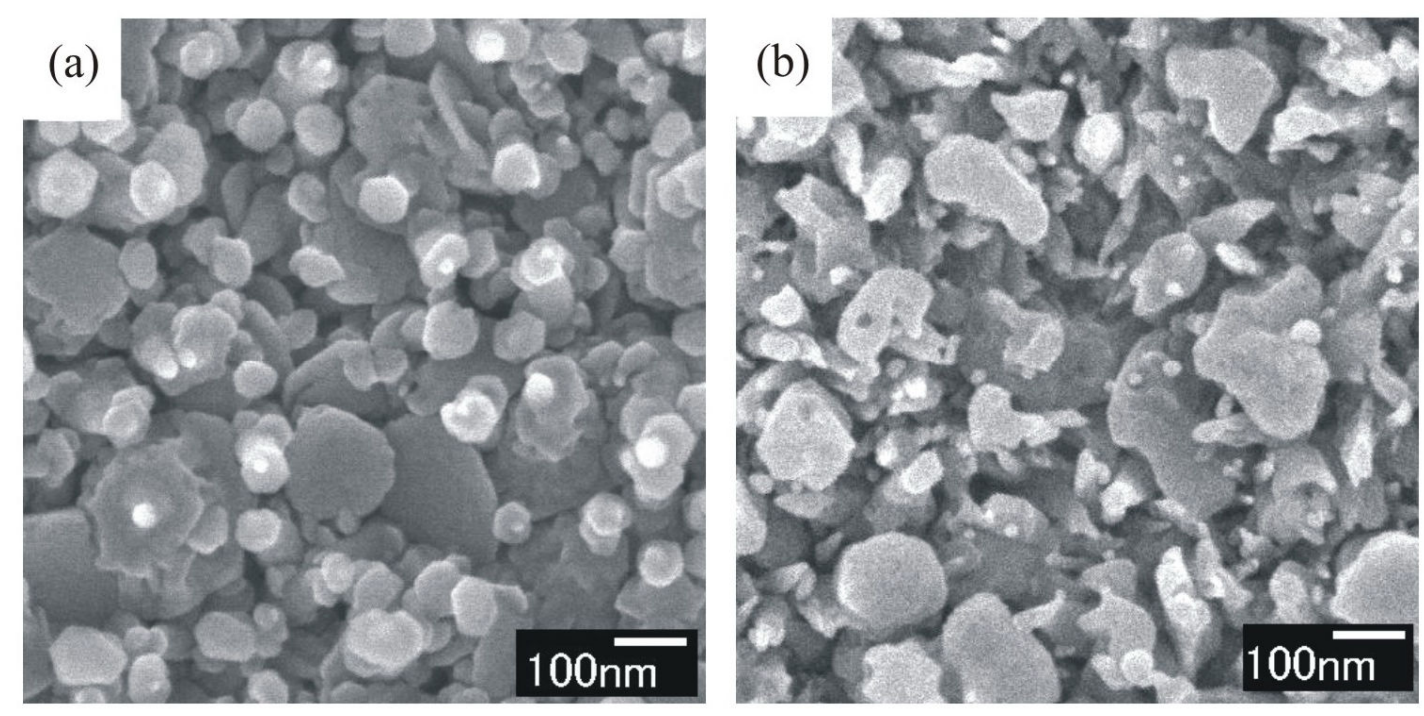

Fig. 2. FE-SEM images of $\mathrm{ZnO}$ surfaces. (a) $\mathrm{ZnO}$ surface before the treatment. (b) Au nanoparticles attached $\mathrm{ZnO}$ surface after the seed-mediated growth treatment.

Principal non-linear optical features. In the Fig. 3 principal results concerning the time dependence of the output photoinduced second order optical susceptibilities are presented. We have found that the optimal angle between the incident seeding beams with fundamental $(\omega)$ and doubled frequency beams are equal to about 72 degree. So we deal with the slipping propagation of the incident beams. The maximal output photoinduced SHG corresponds to the $50 \mathrm{deg}$. As a reference sample we have taken the $\mathrm{LiNbO}_{3}$ films with the known parameters of the second-order optical susceptibility. Angle between the two mentioned beams was equal to about 24 degree and their polarizations were perpendicular. The effective non-linear grating is formed within the films and on the interfaces with thickness about 20-30 nm separating the $\mathrm{ZnO}-\mathrm{Au}$ film composites and the ITO. To confirm the non-liner optical features of the SHG we have performed the measurements for the different incident fundamental dependences after interruption of the writing beams and we have found the logarthimitic slopes with indices varying within 1.85-1.89. Moreover the decay time of the SHG was equal to about $1.5-2.0 \mathrm{ps}$, which is substantially different to the different kinds of fluorescence emission. We have also studied independently non-linear optical absorption and the changes of the refractive indices, which were less than $10^{-5}$ and the two-photon absorption was about $0.15 \mathrm{~cm} / \mathrm{GW}$. So the main role for the second order hyperpolarizability is proved here. Optimal ratio of power densities fundamental/doubled frequency was about 18.

In the Fig. 4 are given the corresponding temperature dependences of the output SHG versus the temperature. One can clearly see that for the samples possessing Au nanoparticles the values of the SHG substantially increases near the $60^{\circ} \mathrm{C}$ achieving about $25 \mathrm{pm} / \mathrm{V}$. At the same time the $\mathrm{ZnO}$ samples without $\mathrm{Au}$ doping do not show any temperature singularities. Such behaviour may be explained by a specific charge transfer occurring due to introduction of the Au atoms in the $\mathrm{ZnO}$.

Such effect may be considered like a rare possibility of enhancement of the second order optical effects ion the $\mathrm{ZnO}$ films. 


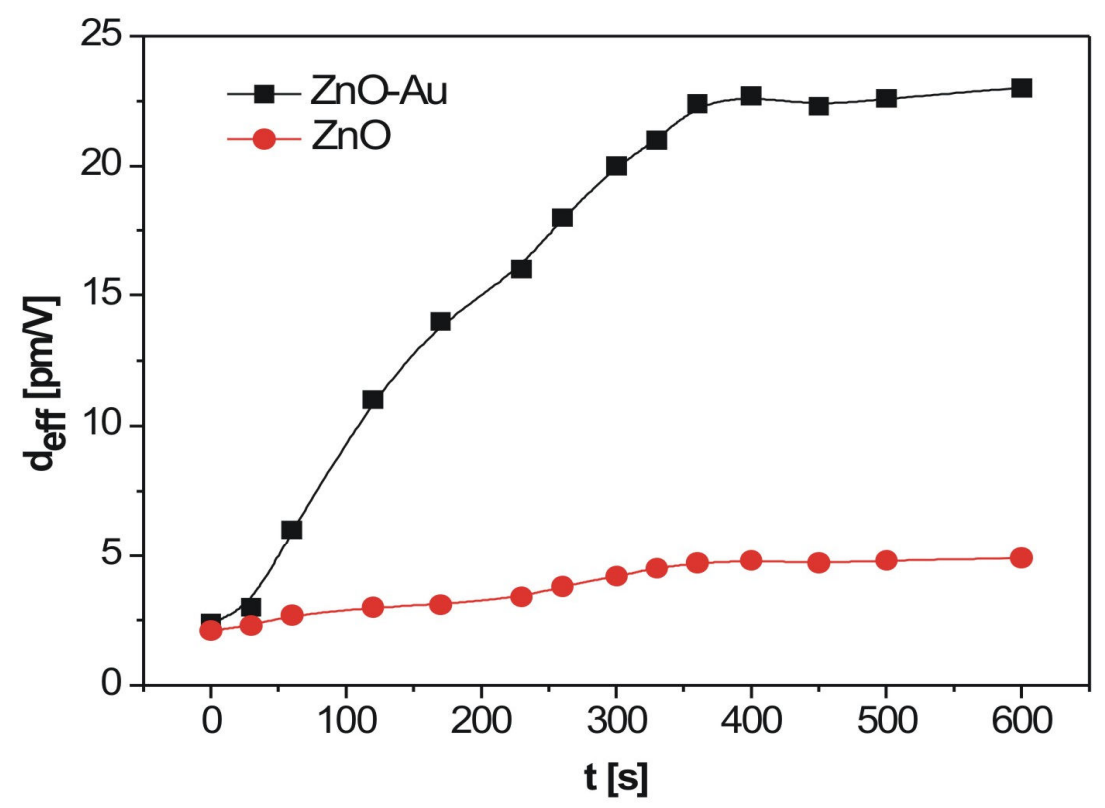

Fig. 3. Dependence of the output second order susceptibilities versus the time of the treatment for the pure and $\mathrm{Au}$ doped $\mathrm{ZnO}$ films.

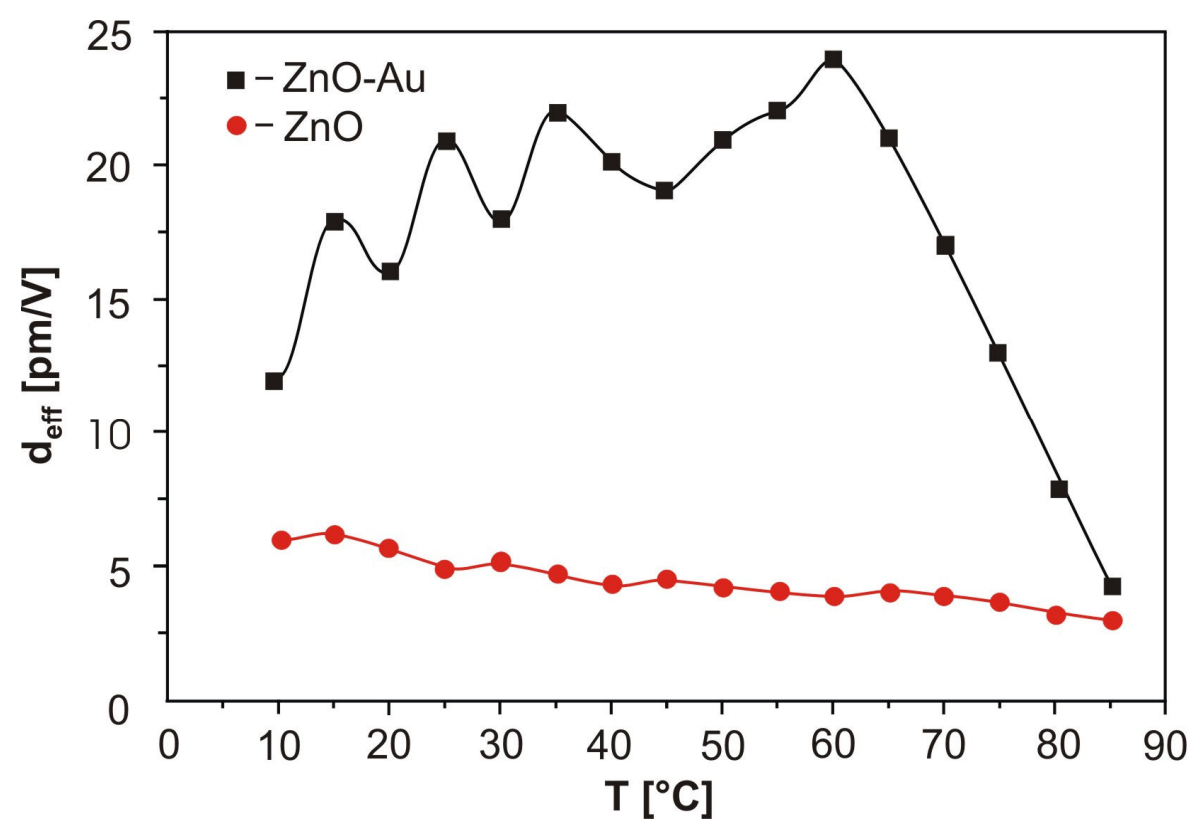

Fig. 4. Temperature dependence of the output second order optical susceptibility for the Au doped $\mathrm{ZnO}$ and for the pure $\mathrm{ZnO}$ nanocrystals.

One can expect appearance of reconstructed near-the-surface structure possessing structural fragments corresponding to thermodynamically metastable (or even unstable) states. Usually optimization of the structure with inclusion of different molecular dynamics method consists in variation of principal structural parameters (bond lengths, angles, torsion angles etc.) to find a structural conformation corresponding to minimum of total energy. For the case of the $\mathrm{ZnO}$ we have the bulk-like perfect crystallites to which one can apply principles of long-range ordered translation symmetry. However, the long-range ordering usually is break in the interface region. 
(a)

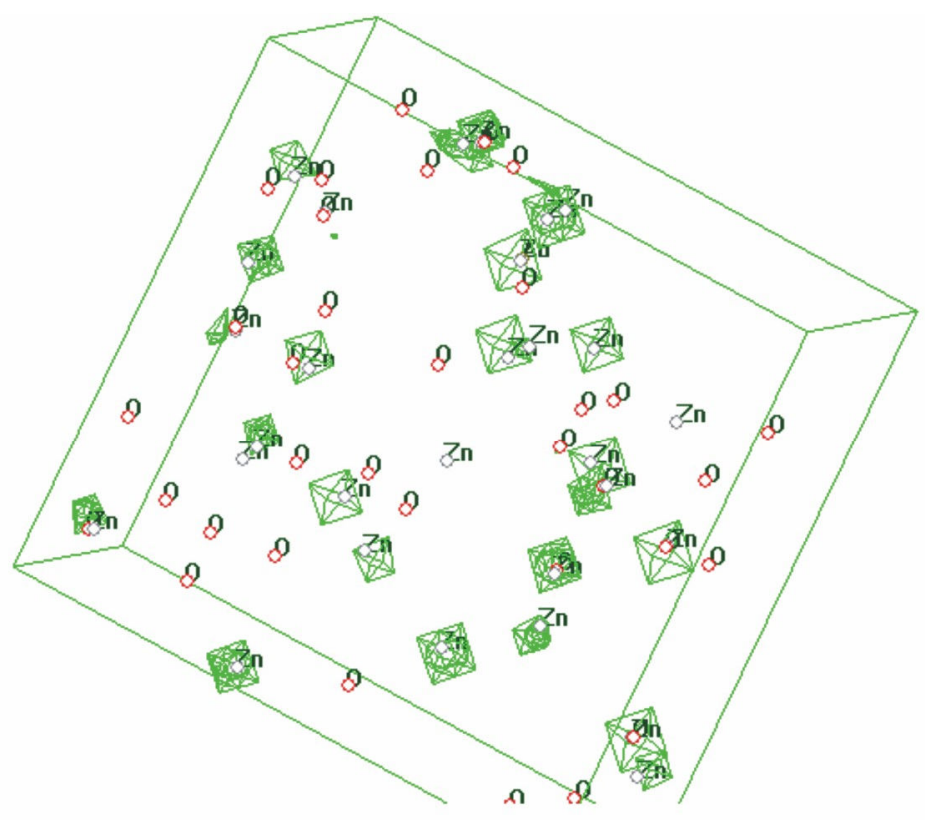

(b)

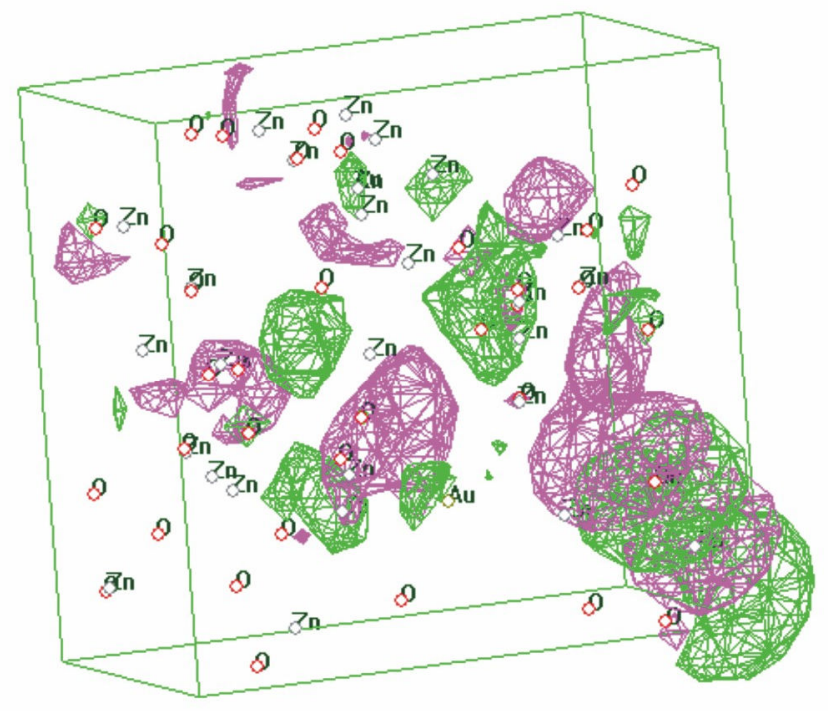

Fig. 5. (a) Charge density distribution for the $\mathrm{ZnO}$ nanocrystallites simulated by Langevin Dynamics and calculated within the LDA DFT method. The grid corresponds to a scale $0.1 \mathrm{e} / \Omega$. (b) Appearance of the charge density non-centrosymmetry due to introduction of the Au atoms. The different colors determine the deviations of the electrostatic charge from the equilibrium positions.

To perform structural optimization of such structure we have done the appropriate MD simulations following Ref. 25. The basic principle of approach in a use of equilibrium thermodynamics with non-equilibrium perturbation created by surrounding disordered background and are described in the Ref. 25. The method may be applicable for many semiconductors and take into account a superposition of several structural fragments renormalized by appropriate weighting factors. Main principle of the approach consists in a choosing of several coordinated layers (usually not more than $6 \mathrm{~nm}$ ) possessing perfect long-range ordering. To the border crystalline layers are added 2-3 layers which are structurally disordered. The geometry optimization is performed 
between the ordered crystalline layer and disordered ones assuming a fixed atomic positions for the crystalline layers.

From the Fig. 5 one can clearly how introduction of the Au atoms would change the principal parameters of the $\mathrm{NC}$ charge density distribution. The occurrence of the temperature maximum may indicate on the several softening of the $\mathrm{ZnO}$ structure which allows to perform more slightly the observed modifications. Moreover substantial role also may play band energy flattering typical for the semiconducting nanaocrystallites [26].

\section{Summary}

Using coherent bicolor interactions we have investigated the photoinduced SHG in Au nanoparticledeposited $\mathrm{ZnO}$ nanocrystallite films. We have found that introduction of the $\mathrm{Au}$ would lead to appearance of substantial redistribution of the charge density. The maximum second-order optical susceptibility was achieved at about $65^{\circ} \mathrm{C}$ and it may reflect several softening of the structures in this temperature range. The performed band energy calculations explain the obtained dependences following the occurrence of the charge density non-centrosymmetry due to incorporation of the $\mathrm{Au}$ atoms.

\section{References}

[1] Ryasnyansky, B. Palpant, S. Debrus, R. Ganeev, A.Stepanov, N. Can, C. Buchal, S. Uysal, Nonlinear optical absorption of $\mathrm{ZnO}$ doped with copper nanoparticles in the picosecond and nanosecond pulse laser field, Applied Optics, 44 (2005) 2839-2845.

[2] Y.B Han, J.B. Han, S.Ding, D.J. Chen, Q.Q Wang, Optical nonlinearity of ZnO microcrystallite enhanced by interfacial state, Optics Express, 13 (2005) 9211-9216.

[3] M.C Larciprete, D. Haertle, A. Belarodini, A.Bertolotti, F .Sarto, P. Gunter, Characterization of second and third order optical nonlinearities of $\mathrm{ZnO}$ sputtered films, Appl. Phys. B: Lasers and Optics 82 (2006) 431-437.

[4] O.G Morales-Saavedra, L. Castaneda, Second harmonic generation of fluorine-doped zinc oxide thin films grown on soda-lime glass substrates by a chemical spray technique, Opt. Communication, V.269, (2007), 370-377.

[5] R.C. Miller, W.A. Nordland, Absolute Signs of Second-Harmonic Generation Coefficients of Piezoelectric Crystals, Phys. Rev. B 2 (1970) 4896-4902.

[6] V. Kapustianyk, B. Turko, A. Kostruba, Z. Sofiani, S. Dabos-Seignon, B. Barwinski, Yu. Eliyashevskyi, Influence of size effect and sputtering conditions on the crystallinity and optical properties of $\mathrm{ZnO}$ thin films, Optics Commun. 269 (2007) 346-350.

[7] H. Cao, J.Y. Wu, H.C. Ong, J.Y. Dai, R.P.H. Chang, Second harmonic generation in laser ablated zinc oxide thin films, Appl. Phys. Lett. 73 (1998) 572.

[8] L. Kuluyuk, I. Kravetsky, A. Micu, E. Koryaev, V. Moshnyga, I. Horoshun, I. Muscutariu and V. Sosoliuc, Nonlinear optical characterization of zinc oxide thin films on $\mathrm{MgO}$ substrates, Proc. SPIE, 2801 (1996) 135-143.

[9] A. Mitra, Raj K. Thareja, Dependence of second harmonic generation on size of nanocrystallites of ZnO, Mod. Phys. Lett. B15 (2001) 515-521.

[10] I.V. Kityk, J. Ebothe, A. Elchicou, Nonlinear Opt. 28 (2001) 515.

[11] U. Neumann, R. Grunwald, U. Griebner, G. Steinmeyer, W. Seeber, Second-harmonic efficiency of ZnO nanolayers, Appl. Phys. Lett. 84 (2004) 170. 
[12] U. Neumann, R. Grunwald, U. Griebner, G. Steinmeyer, M. Scmidbauer, W. Seeber, Secondharmonic performance of $a$-axis-oriented $\mathrm{ZnO}$ nanolayers on sapphire substrates, Appl. Phys. Lett. 87 (2004) 171108.

[13] X.Q. Zhang, Z.K. Tang, M. Kawasaki, A. Ohtomo, H. Koinuma, Resonant exciton secondharmonic generation in self-assembled $\mathrm{ZnO}$ microcrystallite thin films, J. Phys.: Condens. Matter. 15 (2003) 5191-5196.

[14] I.V.Kityk, J.Ebothe, Ael Hichou, M.Addou, A.Bougrine, B.Sahraoui, Linear Electro-Optics Effect in ZnO-F Film-Glass Interface, Physica Status Solidi 234 B (2002) 553-562.

[15] G. Wang, G.T. Khiehne, G.K.L. Wong, J.B. Ketterson, X. Liu, R.P.H. Chang, Large second harmonic response in $\mathrm{ZnO}$ thin films, Appl. Phys. Lett. 80 (2002) 401-403.

[16] J.Ebothe, I.V.Kityk, S.Benet, B.Claudet, K.J.Plucinski, and K.Ozga, Photoinduced effects in $\mathrm{ZnO}$ films deposited on MgO substrates, Optics Communications, 268 (2006) 269-272.

[17] H. Herschel, J. Ebothé, I. V. Kityk and U. Yamoda, Photoinduced second harmonic generation in the $\operatorname{In}_{2} \mathrm{O}_{3}$ crystalline films doped by Al and Sn, Applied Surface Science, $222,(2004), 198-207$.

[18] Kawaharamura, H. Nishinaka, K. Kametani, Y. Masuda, M. Tanigaki and S. Fujita, Fabrication and Properties of $\mathrm{ZnO}$ Thin Films Prepared by Micro Channel Mist Method, J. Soc. Mat. Sci. Jpn. 55, (2006), 153-158.

[19] Y. Kamada, T. Kawaharamura, H. Nishinaka and S. Fujita, Linear Source Ultrasonic Spray Chemical Vapor Deposition Method for Fabrication of $\mathrm{ZnMgO}$ Films and Ultraviolet Photodetectors, Jpn. J. App. Phys. 45 (2006) L857-L859.

[20] M. Kambayashi, J. Zhang, and M. Oyama, Crystal Growth of Gold Nanoparticles on Indium Tin Oxides in the Absence and Presence of 3-Mercaptopropyl-trimethoxysilane, Cryst. Growth Des. 5 (2005) 81-84.

[21] N. R. Jana, L. Gerheart and C. J. Murphy, Wet Chemical Synthesis of High Aspect Ratio Cylindrical Gold Nanorods, J. Phys. Chem. B 105 (2001) 4065 - 4067.

[22] B. D. Busbee, S. Obare and C. J. Murphy, An Improved Synthesis of High-Aspect-Ratio Gold Nanorods Adv. Mater. 15 (2003) 414-416.

[23] G. Chang, J. Zhang, M. Oyama and K. Hirao, Silver-Nanoparticle-Attached Indium Tin Oxide Surfaces Fabricated by a Seed-Mediated Growth Approach, J. Phys. Chem. B 109 (2005) 1204-1209.

[24] H. Bönnemann, G. Braun, W. Brijoux, R. Brinkmann, A. Schulze Tilling, K. Seevogel, K. Siepen, Nanoscale colloidal metals and alloys stabilized by solvents and surfactants Preparation and use as catalyst precursors, J. Organometallic Chem. 520 (1996) 143-162.

[25] I.V. Kityk, M.Demianiuk, A.Majchrowski, J.Ebothe, P.Siemion, IR-induced second-harmonic generation in PbSe microcrystallites, J. Phys.: Condens. Matter. 16 (2004) 3533-3544.

[26] I.V. Kityk, Specific features of band structure in large-sized $\mathrm{Si}_{2-x} \mathrm{C}_{x}(1.04 \leq x<1.10)$ nanocrystallites, Semicond. Sci. Technol. 18 (2003) 1001-1009. 